Estudios Constitucionales, Año 10, № 1, 2012, pp. 117 - 144.

ISSN 0718-0195

Centro de Estudios Constitucionales de Chile Universidad de Talca

"Supremacía constitucional y aplicación judicial de la Constitución en los

Estados Unidos: objeciones a la judicial supremacy"

Luis Alejandro Silva Irarrázaval

\title{
SUPREMACÍA CONSTITUCIONAL Y APLICACIÓN JUDICIAL DE LA CONSTITUCIÓN EN LOS ESTADOS UNIDOS: OBJECIONES A LA JUDICIAL SUPREMACY $\left(^{1}\right)$
}

\author{
JUDICIAL SUPREMACY AND JUDICIAL APPLICABILITY OF THE CONSTITUTION \\ IN THE United STATES: OBJECTIONS TO THE JUDICIAL SUPREMACY.
}

\author{
Luis Alejandro Silva IrarrázaVal $\left({ }^{2}\right)$. \\ Profesor de Derecho; Facultad de Derecho Universidad de Los Andes \\ lsilva@uandes.cl
}

RESUMEN: La garantía de la Constitución descansa definitivamente en el Poder Judicial, porque la Constitución escrita es ley y es deber del juez aplicar la ley. Pero además, por ser la Constitución ley suprema, la interpretación judicial de la Constitución es suprema también. Luego, la misma naturaleza de la Constitución-ley escrita y suprema-implicaría la supremacía del poder judicial-judicial supremacy-por sobre los demás poderes estatales y federales, porque su interpretación de la Constitución prevalecería por sobre cualquier otra. En este artículo discutimos esta conclusión, en el contexto del Derecho Constitucional norteamericano. Analizando los fundamentos de la judicial supremacy, se quiere demostrar que la naturaleza de la Constitución no implica necesariamente que sea un tribunal -la Corte Suprema federal, en última instancia- quien interprete su significado en forma definitiva. Las tres notas características de la Constitución-escrita, normativa y suprema-admiten otra lectura, que no conduce a la afirmación de la judicial supremacy como consecuencia inevitable.

ABSTRACT: The guarantee of the Constitution lies definitively in the judiciary, because the written Constitution is law and the duty of the judge is to say what the law is. In addition, as the Constitution is the supreme law, judicial interpretation of the Constitution is supreme as well. Then, the very nature of the Constitution-supreme, normative and written-involve the supremacy of the judiciary over other state and federal powers, because their interpretation of the Constitution prevail over any other -that it's judicial supremacy. In this paper we discuss this finding, in the context of American constitutional law. Analyzing the foundations of judicial supremacy is to demonstrate that the nature of the Constitution does not necessarily means that it is a court-finally, the federal Supreme Court-the ultimate interpreter of its meaning. The three characteristic features of the Constitution - written, normative and supreme-, admit another reading, which leads not to the assertion of judicial supremacy as unavoidable.

\footnotetext{
${ }^{1}$ Este artículo es resultado de un proyecto de investigación financiado por la Dirección de Investigación de la Universidad de los Andes. Presentado el 25 de agosto de 2011 y aprobado el 23 de noviembre de 2011.

${ }^{2}$ Profesor de Derecho Constitucional de la Facultad de Derecho de la Universidad de los Andes. Mail: 1silva@ uandes.cl. Quiero agradecer al profesor Sergio Verdugo sus observaciones, y a Vicente Yubini, mi ayudante, por su dedicación al proyecto.
} 
PalabRas CLAVE: Supremacía Judicial; Supremacía Constitucional; Corte Suprema

KEY WORDS: Judicial Supremacy; Constitution Supremacy; Supreme Court

\section{INTRODUCCIÓN}

En Estados Unidos la defensa de la Constitución está prácticamente entregada a la Corte Suprema federal. Esta interpreta su texto a través de sentencias que tienen efectos vinculantes no sólo para las partes del juicio, sino para todos los restantes poderes del país, estatales y federales. Las sentencias de la Corte Suprema federal son la última palabra sobre el significado de la Constitución; su interpretación prevalece sobre la interpretación del ejecutivo y del legislativo. Por esto, en Estados Unidos se habla de la supremacía del poder judicial (judicial supremacy).

La doctrina de la judicial supremacy descansa principalmente en la sentencia Marbury v. Madison, en la que John Marshall sentó las bases de la judicial review. Este poder del juez para aplicar la Constitución contra la ley parece que se funda en la naturaleza misma de la Constitución. Porque la Constitución es ley, y el deber esencial del juez es aplicar la ley, el juez debe aplicar la Constitución. Pero como además la Constitución es suprema, el juez debe preferirla a la ley en caso de incompatibilidad entre ambas. A esto debe agregársele el efecto natural de cualquier sentencia en la tradición del common law, que es determinar el sentido de la norma interpretada para futuros casos similares, por el principio del stare decisis; con valor supremo en este caso, por tratarse de la norma suprema.

Los fundamentos de la judicial supremacy parecen demostrar en forma inequívoca, que esta doctrina emana como consecuencia necesaria de la naturaleza de la Constitución. No importa si gusta poco o mucho, porque es inevitable. Pero aquí se discute esto: la Constitución no implica necesariamente que su guardián último sea el Poder Judicial. Es verdad que si se aceptan las premisas de la judicial supremacy, el corolario es la supremacía del judicial, porque el argumento está bien construido y la conclusión no es falaz. Pero si no se aceptan las premisas, la conclusión es otra.

Tres son las premisas que se cuestionan, en cuanto supondrían lógicamente la judicial supremacy: el carácter escrito de la Constitución, su carácter normativo y su carácter supremo. Ni el hecho de ser la Constitución escrita, ni normativa ni suprema implica que su interpretación definitiva esté en manos de la Corte Suprema federal. Esto no significa negar la posibilidad (o el hecho) de la judicial supremacy, sino la naturaleza de la Constitución como su fundamento lógico normativo. Este trabajo pretende demostrar que las premisas invocadas para afirmar la judicial supremacy como efecto ineludible de la Constitución son equívocas y, por lo tanto, no concluyentes. 
La exposición está dividida en dos partes. La primera de ellas presenta la doctrina de la judicial supremacy y sus premisas, en cuanto postulan el carácter necesario de ella, dada la naturaleza de la Constitución. En esta primera parte, analizamos cuatro elementos, que en la formulación de la judicial supremacy son interdependientes: el carácter escrito, normativo y supremo de la Constitución y el efecto general y vinculante de las sentencias judiciales que la interpretan. Los tres primeros están en la sentencia Marbury v. Madison y el cuarto en la sentencia Cooper v. Aaron. La segunda parte de la exposición desarrolla las objeciones a cada una de las premisas de la judicial supremacy expuestas en la primera parte. Por eso, también la segunda parte se divide en cuatro.

En la doctrina norteamericana, está generalmente aceptado desde hace algunas décadas, que la judicial supremacy no tiene sustento lógico en la naturaleza de la Constitución. ¿Por qué, entonces, este artículo? Los autores que en Estados Unidos defienden el carácter necesario de la judicial supremacy son pocos, y muchos con argumentos diferentes de éstos que aquí se van a discutir. ¿Cómo justificar esta investigación? Sin perjuicio de otras razones, el principal motivo que anima este trabajo es la exploración crítica de unos argumentos que -débiles en los Estados Unidos- en Chile tienen plena vigencia, especialmente en la explicación del poder del Tribunal Constitucional. Por esta razón, la investigación tiene una finalidad propedéutica para entrar, más adelante en el tiempo, al análisis de los fundamentos del poder del Tribunal Constitucional chileno como garante final de nuestra Constitución.

\section{LA DOCTRINA DE LA SUPREMACÍA JUdiCIAL EN LOS Estados Unidos}

\section{A. La formulación de la judicial supremacy}

La Constitución federal de 1787 es la ley fundamental de los Estados Unidos de Norteamérica. Es la norma suprema a la que deben conformarse todas las otras normas y sujetarse todos los poderes, particularmente el legislador. La conformidad con la Constitución es una condición de la validez de las leyes: "This Constitution and the Laws of the United States which shall be made in Pursuance thereof (...) shall be the supreme Law of the Land (...)" (art. VI sect. 2); y los jueces están obligados por la Constitución federal, no importa lo que digan en contrario las leyes: "the Judges (...) shall be bound thereby, any Thing in the Constitution or Laws of any State to the Contrary notwithstanding" (art. VI sect. 2).

La Constitución no dice quién tiene el poder para declarar que una ley es contraria a la Constitución pero, de todos modos, la Constitución se concibió originalmente como un límite eficaz contra la omnipotencia del legislador. ¿Cómo garantizar la eficacia de la Constitución respecto del legislador, si la Constitución 
no dice quién vela por ello? La Corte Suprema dio la respuesta en la sentencia Marbury v. Madison: ${ }^{3}$ corresponde al Poder Judicial rechazar la aplicación de las leyes inconstitucionales. Con el tiempo, este poder se llamaría judicial review.

Entre las premisas de la judicial review se encuentra ésta: "It is emphatically the province and duty of the judicial department to say what the law is" (5 U.S. 137, 179). Y puesto que la Constitución es law, corresponde a los jueces aplicar la Constitución, lo cual implica interpretarla, porque "Those who apply the rule to particular cases, must of necessity expound and interpret that rule" (5 U.S. 137, 178).

La judicial review presupone que la interpretación judicial de la Constitución prevalece sobre la interpretación legislativa de la Constitución. Desde este punto de vista, puede afirmarse que la judicial review expresa una relativa superioridad del Poder Judicial respecto del legislativo. Esta supremacía interpretativa de la Constitución es una consecuencia inevitable de su garantía jurisdiccional.

Pero, ¿`cuál es el alcance de la interpretación judicial de la Constitución? En otras palabras, ¿en qué se traduce esta supremacía del judicial sobre el legislativo? Aunque la respuesta se puede dar de muchas maneras, básicamente significa que el legislador está obligado a respetar la interpretación judicial, y no puede alterarla a través del procedimiento legislativo ordinario. ${ }^{4}$ En este sentido, la judicial review parece suponer la supremacía del judicial, porque el juez no podría invalidar una ley sin que su visión de la Constitución tenga mayor valor que la que es invalidada. ${ }^{5}$

En cierto modo, a través de la judicial review, la Corte interpreta lo que la Constitución significa para el legislador, porque el legislador no puede desconocer la interpretación judicial de la Constitución. En este contexto, se entiende bien lo que quiso decir el entonces Gobernador Hughes en 1907: "We are under a Constitution, but the Constitution is what the judges say it is" (Hughes; 1908, p. 139). ${ }^{6}$

De manera aparentemente inevitable, la Constitución significa lo que los jueces dicen que es. La naturaleza normativa y suprema de la Constitución entraña el poder de los jueces para declarar el sentido definitivo de la Constitución. Dicho de otro modo, las sentencias de la Corte son como leyes, por su efecto general y

\footnotetext{
${ }^{3} 5$ U.S. (1Cranch) 137 (1803).

${ }^{4}$ O'SCannlain (2005), p. 794. En Dickerson v. United States 530 U.S. 428 (2000) la Corte declaró que el Congreso no tiene el poder para desconocer la interpretación que ella ha hecho de un derecho constitucional.

${ }^{5}$ WARD (2006), p. 4.

${ }^{6}$ Luego sería Chief Justice, entre 1930 y 1941.
} 
vinculante. La expresión más clara de esta consecuencia es de la propia Corte, en la sentencia Cooper v. Aaron. ${ }^{7}$

En Cooper v. Aaron, la Corte Suprema estableció que un principio asentado en Marbury y desde entonces respetado es la primacía de la interpretación judicial de la Constitución: "the federal judiciary is supreme in the exposition of the law of the Constitution, and that principle has ever since been respected by this Court and the Country" (358 U.S. 1, 19). De este principio se sigue que la interpretación judicial tiene el mismo rango que la Constitución: "It follows that the interpretation (...) enunciated by this Court (...) is the supreme law of the land" $(358$ U.S. 1, 19) y, por lo tanto, vinculante para todos los obligados por juramento a respetar la Constitución.

Los elementos que configuran este poder por el que prácticamente se identifica la Constitución con su interpretación judicial es lo que puede entenderse como la doctrina de la judicial supremacy. ${ }^{8}$ Sostenida por diversas razones y circunstancias, la Corte Suprema dice la última palabra sobre lo que la Constitución es; las diferentes interpretaciones constitucionales que pueden enfrentarse son definitivamente resueltas por las sentencias de la Corte Suprema federal.

La Corte Suprema ha sido la defensora más decidida de su propio poder y quien lo ha caracterizado en sus principales rasgos. Esta afirmación de su supremacía tiene distintas formulaciones: la Corte puede invalidar un acto del legislador;' la Corte es intérprete final de la Constitución; ${ }^{10}$ sólo la Corte $-y$ no el Congreso- puede decir qué derechos están amparados por una determinada Enmienda; ${ }^{11}$ los actos del Presidente están sujetos a la revisión de la Corte; ${ }^{12}$ la Corte tiene el deber de asegurar que ningún poder transgreda los límites de la Constitución; ${ }^{13}$ la Corte tiene la responsabilidad de garantizar los derechos individuales; ${ }^{14} \mathrm{el}$ Congreso no

7358 U.S. 1 (1958).

${ }^{8}$ Así lo describe una obra clásica en la materia: "The principles of law and political practice which place the guardianship of the expressed and implied terms of written constitutions primarily in courts of justice, and the dominance of judge-made law in accordance with common-law standards and principles, constitutes the bases of what may appropriately be termed the American doctrine of judicial supremacy". HaINES (1959), pp. 24 y 25. Cursivas en el original.

${ }^{9}$ Marbury v. Madison 1 Cranch 137 (1803).

${ }^{10}$ Baker v. Carr 369 U.S. 186 (1962).

${ }^{11}$ City of Boerne v. Flores 521 U.S. 507 (1997).

${ }^{12}$ United States v. Nixon 418 U.S. 683 (1974).

${ }^{13}$ Hutchinson v. United States 369 U.S. 599 (1962).

${ }^{14}$ Bell v. Maryland 378 U.S. 226 (1964). 
puede reemplazar la interpretación que la Corte ha hecho de un derecho constitucional. ${ }^{15}$ Toda esta doctrina jurisprudencial se extrae y apoya en Marbury. ${ }^{16}$

La judicial supremacy es una doctrina de fundamentos esencialmente jurisprudenciales: fue la propia Corte Suprema quien a través de sus sentencias se atribuyó a sí misma la facultad para declarar el significado de la Constitución con efecto general y vinculante. El entramado teórico que sostiene la judicial supremacy está construido de manera que esta doctrina parece ser la consecuencia lógica de la naturaleza de la Constitución y, por tanto, inevitable e indiscutible. Esto es lo que ahora vamos a examinar de cerca.

\section{B. El soporte argumentativo de la judicial supremacy}

En este apartado, quiero analizar los argumentos contenidos en dos sentencias capitales de la judicial supremacy: Marbury v. Madison (1803) y Cooper v. Aaron (1958). En estas dos decisiones se contienen los elementos esenciales de la doctrina que sostiene a la Corte como el intérprete final de la Constitución.

\section{Marbury v. Madison}

El primer fundamento de la judicial supremacy es la sentencia Marbury v. Madison. El punto central de esta sentencia, que es el poder de la Corte para decir lo que la Constitución es, descansa en la naturaleza de la propia Constitución. Del carácter normativo, escrito y supremo de la Constitución, Marshall dedujo el poder del juez para exponer el significado de la Constitución y rehusar la aplicación de la ley que la infringe.

No es extraño que la sentencia que es señalada por haber consagrado definitivamente la judicial review y sentado las bases de su evolución, sea a la vez fundamento capital de la judicial supremacy. Porque el poder para juzgar la constitucionalidad de las leyes y decidir su aplicación expresa una superioridad del judicial por sobre el legislador, al menos respecto de la fuerza de la interpretación de la Constitución. ${ }^{17}$

Para facilitar la explicación de los fundamentos que se hallan en Marbury, examinaré por separado cada uno de los tres atributos de la Constitución que Marshall consideró decisivos para afirmar el poder de la Corte. Es preciso advertir,

\footnotetext{
${ }^{15}$ Dickerson v. United States 530 U.S. 428 (2000).

${ }^{16}$ Cuinton (1989) analiza la función de Marbury v. Madison en el desarrollo de la jurisprudencia de la Corte. Respecto de la judicial supremacy, pp. 121-125, especialmente p. 124.

${ }^{17}$ Por esto, aunque la judicial review y la judicial supremacy son cosas distintas, sus fundamentos son compartidos. De allí que sea necesario estudiar la sentencia Marbury.
} 
en todo caso, que ninguno de ellos puede ser exactamente acotado, por lo que una relativa superposición entre ellos es inevitable.

\section{a) La Constitución escrita}

La Constitución se puso por escrito para que la voluntad del pueblo que le dio su origen fuera conocida. ${ }^{18} \mathrm{Y}$ esta voluntad fue asegurar la libertad, en función de la cual -entre otras cosas- se fijó el límite de actuación de cada uno de los poderes del Estado. Particularmente significativo de esta nueva Constitución fue limitar el Poder Legislativo. ${ }^{19}$

Afirma Marshall en Marbury: "The powers of the legislature are defined and limited; and that those limits may not be mistaken or forgotten, the Constitution is written" (5 U.S. 137, 177). La Constitución se puso por escrito para asegurar que el Poder Legislativo respetara los límites definidos por el pueblo. En Estados Unidos no debía ocurrir como con el Parlamento inglés, que el Congreso fuera soberano: el Congreso debía estar limitado por la Constitución, y por eso se puso por escrito. ${ }^{20}$

En Marbury, Marshall no dijo nada nuevo; nadie entonces dudaba de que la Constitución escrita fuera un límite al legislador. La única innovación que introdujo fue el énfasis en el carácter escrito de la Constitución. ${ }^{21}$ Hasta entonces, la eficacia de la Constitución no dependía de que ésta estuviera puesta por escrito. ${ }^{22}$ La Constitución limitaba al legislador porque era la Constitución, no porque fuera escrita. Pero Marshall introdujo un sutil matiz que luego serviría como premisa de la judicial supremacy: "Certainly all those who have framed written constitutions contemplate them as forming the fundamental and paramount law of the nation, and consequently the theory of every such government must be, that an act of the

\footnotetext{
${ }^{18}$ McDowell (2010), p. 322

${ }^{19}$ Los framers tuvieron en especial consideración el caso inglés, en que el Parlamento es soberano. La propia experiencia mientras fueron colonias inglesas fue una razón importante para querer impedir cualquier arbitrariedad del legislador.

${ }^{20}$ En comparación con Inglaterra, podría deducirse que el carácter escrito de la Constitución es condición de su aplicación preferente. La ausencia en Inglaterra de una Constitución escrita explicaría que allí no exista judicial review. En cambio, en los Estados Unidos la existencia de una Constitución escrita sería la causa condicionante de la existencia de la judicial review.

${ }^{21}$ SNOWISS (1990), p. 109. La generosa referencia de Marshall al carácter escrito de la Constitución es uno de los elementos que marcan el inicio de un nuevo periodo de la judicial review: SNOWISS (1990), p. 113.

${ }^{22}$ De hecho, se practicó la judicial review en algún estado sin Constitución escrita: Kamper v. Hawkins 1 Va. Cases 20 (1793), en SNOwISS (1990), p. 27.
} 
legislature repugnant to the constitution is void. This theory is essentially attached to a written constitution" (5 U.S. 137, 178). ${ }^{23}$

Al enfatizar el carácter positivo de la Constitución, Marshall acentuó la semejanza entre la Constitución y la ley ordinaria, con lo cual facilitó la justificación de la defensa judicial de la Constitución (como si de una ley se tratara). Privilegiando el texto más que los principios que la inspiran, Marshall transformó la garantía de la Constitución en una responsabilidad judicial y puso los fundamentos de la judicial supremacy.

La importancia que Marshall atribuyó al texto de la Constitución fue una novedad cuyos alcances no fueron percibidos en su época: nunca antes de Marshall la Corte se apoyó en su propia exposición del texto constitucional por sobre una exposición plausible de la ley en sentido contrario. ${ }^{24} \mathrm{Y}$ esta exposición del texto de la Constitución, por la natural semejanza que guarda con la ley ordinaria, está dirigida por las reglas de interpretación y aplicación de la ley. ${ }^{25}$

Sería un error pensar que Marshall dedujo del carácter escrito de la Constitución el poder de la Corte para interpretar su texto definitivamente. Todavía faltaba mucho para esto. ${ }^{26}$ Pero su insistencia en esta característica de la Constitución y las consecuencias que se siguen (v. gr. las reglas para interpretarla) propició la legalización de la ley fundamental, de la que sí puede deducirse el poder de la Corte para decir la última palabra sobre su significado. ${ }^{27}$

\section{b) La Constitución suprema}

En el caso de la Constitución, la supremacía consiste en ser la regla de validez de las demás normas y tratados. Dice el artículo VI de la Constitución que las leyes y tratados conformes con la Constitución son con ella la ley suprema de la nación (the supreme law of the land). Marshall dedujo que, entonces, las leyes que no sean conformes con la Constitución, no son leyes válidas y, por lo tanto, no pueden ser aplicadas por los jueces.

\footnotetext{
23 "Marbury suggested that judicial authority over unconstitutional acts was inherent in the American constitution's status as a written one". SNOWISS (2001), p. 80.

${ }^{24}$ SNOWISS (1990), p. 125.

${ }^{25}$ SNOwiss (1990), p. 122; MCDowell (2010), p. 331.

${ }^{26}$ Había consenso en que el poder de declarar leyes inválidas no significaba de por sí la supremacía del Poder Judicial: HaINES (1959), pp. 146-147.

${ }^{27}$ Hoy se asocia típicamente el carácter escrito de la Constitución a la supremacía normativa de su texto y la interpretación judicial definitiva de su significado. DAjovic (2010), p. 258.
} 
Los límites constitucionales al Poder Legislativo no significan nada, si es que su infracción no acarrea ninguna consecuencia: "To what purpose are powers limited, and to what purpose is that limitation committed to writing; if these limits may, at any time, be passed by those intended to be restrained?" (5 U.S. 137, 177). O la Constitución es una ley superior al legislador ordinario (y entonces las leyes inconstitucionales son nulas) o la Constitución es un intento absurdo del pueblo por limitar un poder de suyo ilimitable, dice Marshall.

Para Marshall no hay duda de que los actos contrarios a la Constitución son nulos, porque la Constitución se puso por escrito y es esencial a la Constitución escrita su carácter supremo. Hay una interdependencia entre la positivización de la Constitución y su carácter supremo. El poder del legislador está subordinado a la Constitución, y sólo ejercido conforme con ella resulta legítimo. La cuestión es quién decide si la ley es conforme con la Constitución. Marshall definió que es responsabilidad del juez hacerlo.

Si una ley contraria a la Constitución es nula, ¿cómo podrá el juez aplicarla? Frente a la incompatibilidad entre la Constitución y una ley, el juez debe preferir la Constitución, porque es superior. Precisamente porque la esencia de la función judicial es determinar la ley aplicable al caso, es deber del juez aplicar la Constitución y rechazar la ley.

Si la Constitución es norma jurídica y son los tribunales los llamados a aplicar las normas jurídicas, y si además la Constitución es norma suprema, el juez que la aplica deviene supremo también. El significado de la supremacía constitucional adquiere la plenitud de su sentido cuando el juez aplica directa y preferentemente la Constitución. ${ }^{28}$

El carácter supremo de la Constitución implica que su interpretación judicial es suprema también. Si la Constitución es lo que los jueces dicen que es, entonces lo que dicen los jueces es supremo, porque la Constitución es suprema. De aquí que la supremacía de la Constitución sea uno de los fundamentos capitales de la judicial supremacy.

Este es el razonamiento que siguió Cooper v. Aaron, y que luego se ha repetido en otros casos. La condición de intérprete supremo de la Constitución que la Corte reclama para sí, se traduce en la judicial supremacy porque la Constitución es la norma suprema. La supremacía del intérprete es una cualidad relativa a la jerarquía de la norma interpretada.

28 "The supremacy of the judiciary, whether it exists under a federal or a unitary constitution, finds its ultimate logical foundation in the conception of the supremacy of law as distinguished from the possession and exercise of governmental power": CLARK (1903), p. 18. 


\section{c) La Constitución normativa}

Al afirmar Marshall la competencia de la Corte para rehusar la aplicación de una ley inconstitucional, invocó el deber esencial de la función judicial, que es decir lo que la ley es: "It is emphatically the province and duty of the judicial department to say what the law is" (5 U.S. 137, 178). Y la Constitución es ley, al menos respecto de las funciones de los jueces: "So if a law be in opposition to the constitution (...) the court must determine which of these conflicting rules governs the case. This is of the very essence of judicial duty" (5 U.S. 137, 179).

$\mathrm{Si}$ la Constitución no fuera ley, los jueces no podrían aplicarla. La judicial review carecería de base teórica si se rechazara la noción de que la Constitución es ley. ${ }^{29}$ Y la aplicación de la ley implica necesariamente su interpretación. ${ }^{30}$ Luego, de la naturaleza normativa de la Constitución emana el deber del juez de interpretarla y aplicarla. Y de la misma fuente emana la obligación de aceptar como vinculante esa interpretación. ${ }^{31}$

El carácter normativo de la Constitución está intrínsecamente asociado a la idea de su efectividad. Si la Constitución fue diseñada para limitar el poder del legislativo, pero los jueces no pueden garantizar el respeto de esos límites, ¿qué sentido pudo haber tenido hacer una Constitución? Del sentido obvio de la Constitución -v. gr. limitar al legislador- se sigue la competencia de los jueces para aplicar la Constitución.

Pero una cosa es la competencia de los jueces para aplicar la Constitución, y otra cosa distinta es que la interpretación que los jueces hacen de la Constitución sea obligatoria para todos. ¿De qué modo la judicial supremacy se sigue de la judicial review? Un argumento clásico es el de Joseph Story, que podemos sintetizar así: las cortes de los Estados Unidos -y la Corte Suprema en última instanciatienen el poder de interpretar la Constitución, porque su deber es decidir todos los casos que se promuevan bajo ella (Artículo III);32 es un principio del common

\footnotetext{
${ }^{29}$ BLACK (1960), p. 6.

${ }^{30}$ Los jueces nos dicen lo que la Constitución es, porque por definición esa es la descripción de su trabajo Friedman (2004), p. 1289.

${ }^{31}$ Como bien lo resume Snowiss, en la moderna concepción de la judicial review, "The obligation to accept the judicial interpretation of the Constitution comes, it is supposed, from the Constitution's status as the kind of law properly subject to judicial application and interpretation. It comes from inclusion of the Constitution within that kind of law for which it is the province and duty of the judicial department to say what the law is": SNOWISS (1990), p. 182. Incluso entre los enemigos de la judicial supremacy se asume que la concepción de la Constitución como norma entraña necesariamente la primacía del Poder Judicial: THomas (2004).

${ }^{32}$ STORY (1833). Story extiende este argumento sólo para aquellas materias constitucionales susceptibles de ser sometidas al conocimiento y decisión judicial; no todo el texto de la Constitución goza de esta posibilidad, pp. 344-347.
} 
law, que las decisiones judiciales del tribunal supremo establecen la interpretación definitiva de las leyes cuya controversia se ha sometido a su conocimiento, pero además, que el fondo de esa decisión vincula las futuras decisiones en la misma materia; ${ }^{33}$ si las decisiones de la Corte son definitivas y obligatorias para todos los ciudadanos, ¿por qué no habrían de serlo también para los estados en que habitan esos ciudadanos? ${ }^{34}$

No hay ninguna duda acerca de la competencia de los jueces para aplicar la ley ni de la necesidad de respetar sus sentencias, con independencia de la opinión que nos merezcan. Se entiende que es una exigencia de la propia tradición jurídica -y del orden social, en definitiva-, esta de aceptar que una decisión clausure un debate definiendo la regla aplicable, y su sentido y alcance. Esto que se dice de la ley sin vacilaciones, se dice también de la Constitución. ${ }^{35}$

La eficacia de la Constitución como límite del legislador depende de la eficacia de las sentencias que la interpretan, del mismo modo que la eficacia de la ley depende en último término de la eficacia de su aplicación judicial. Y las mismas razones que justifican el acatamiento de las sentencias que interpretan la ley, justifican el acatamiento de las sentencias que interpretan la Constitución. Así, resulta que el efecto vinculante de la interpretación judicial de la Constitución emana de su misma naturaleza.

\section{Cooper v. Aaron}

Poco más de un siglo y medio después de Marbury v. Madison, la Corte Suprema amplió el alcance de su poder con una nueva sentencia. Se trata de Cooper v. Aaron, en la que interpretando la doctrina de Marbury v. Madison, definió que la interpretación que la Corte Suprema hace de la Constitución es suprema como la Constitución misma y, por lo tanto, vinculante para todos los oficiales públicos.

La Corte Suprema se vio hasta cierto punto obligada por las circunstancias a declarar que sus decisiones eran vinculantes como la Constitución lo es. El desacato del Estado de Arkansas a la sentencia Brown v. Board of Education, manifestado

\footnotetext{
33 STORY (1833), p. 349.

${ }^{34}$ STORY (1833), p. 350.

35 "An important aspect of the Constitution, as of all law, is its authority, and intrinsic to the concept of authority is that it provides content-independent reasons for action. Accordingly, an authoritative constitution has normative force even for an agent who believes its directives to be mistaken. What is rarely noticed, however, is that the same argument applies to authoritative interpreters of the Constitution as applies to the Constitution itself. Just as it is often right for officials to obey constitutional provisions they believe wrong, so too is it often right for officials to obey judicial interpretations they believe wrong": ALEXANDER y SCHAuER (1998), p. 1361.
} 
en su obstinación por impedir el plan de integración racial implementado por la escuela de Little Rock respaldado por la propia Corte, fue la circunstancia que motivó esta declaración unánime y sin precedente. ${ }^{36}$

$\mathrm{El}$ argumento de que se valió la Corte para justificar el valor imperativo de sus decisiones está contenido en el siguiente párrafo: "[Marbury v. Madison] declared the basic principle that the federal judiciary is supreme in the exposition of the law of the Constitution, and that principle has ever since been respected by this Court and the Country as a permanent and indispensable feature of our constitutional system. It follows that the interpretation (...) enunciated by this Court (...) is the supreme law of the land, and Art. VI of the Constitution makes it of binding effect on the States 'any Thing in the Constitution or Laws of any State to the Contrary notwithstanding"' (358 U.S. 1, 19).

Con esta sentencia, la Corte Suprema se autoproclama intérprete supremo de la Constitución, con fundamento en la misma naturaleza de la Constitución. En otras palabras, la Corte interpreta definitivamente la Constitución porque la Constitución es norma escrita y suprema. Aunque Marbury no haya dicho lo que la sentencia Cooper le atribuye, lo cierto es que la declaración de Cooper no es caprichosa. En realidad, es el resultado lógico del curso que tomaron los precedentes sentados por Marshall en Marbury. La autoproclamación de la Corte como intérprete supremo y vinculante de la Constitución es el punto culminante del proceso de legalización de la Constitución, de la transformación de la Constitución en ley. ${ }^{37}$

El valor vinculante -supremo- de la interpretación judicial de la Constitución, responde a la misma necesidad que justifica tener una Constitución de naturaleza normativa. Así como la función de la ley (prescribir imperativamente lo que debe hacerse o evitarse) se justifica por su fin (garantizar condiciones de orden social), la interpretación judicial de la Constitución debe ser imperativa, porque si no, el fin de la Constitución (que es ley) queda incumplido. ${ }^{38} \mathrm{Si}$ la Constitución carece de un intérprete final de naturaleza judicial, queda privada de efecto. En un concierto de intérpretes de la Constitución, donde ninguno tiene la palabra final, el

\footnotetext{
${ }^{36}$ Para mayores referencias del caso (Freyer, 2008; Kilpatrick, 2008; Roosvelt III, 2008; Farber, 1982).

${ }^{37}$ SNOWISS (1990), p. 196.

38 "The reasons for having laws and a constitution that is treated as law are accordingly also reasons for establishing one interpreter's interpretation as authoritative. Cooper v. Aaron thus reflects the very reason for having a constitution that is regarded as law", AleXAnder y SCHAUer (1997), p. 1377. La finalidad de la Constitución como justificación de la judicial supremacy, puede entenderse de maneras distintas. Por ejemplo, para alguno está ordenada a conservar la federación (KeNT; 1896, pp. 364-365; DiceY; 1902, pp. 170 y ss.) y para otro asegurar estabilidad (AleXANDER y SCHAUER; 1997, pp. 171 y ss.)
} 
resultado es el desconcierto. De allí que la naturaleza misma de la Constitución exija un intérprete definitivo. ${ }^{39}$

Después de haber examinado los principales fundamentos de la judicial supremacy, corresponde exponer las objeciones. Quiero precisar que las objeciones que vamos a tratar a continuación no tienen nada que ver con aquellas que se dirigen a cuestionar la posición de la Corte como intérprete final de la Constitución (aunque, obviamente, algunas puedan coincidir más o menos). Nuestras objeciones tienen por finalidad discutir que la fuente de la judicial supremacy sea la naturaleza de la Constitución.

\section{LAS OBJECIONES A LA JUDICIAL SUPREMACY}

En este apartado, quiero detenerme en las objeciones a las premisas que sustentan la judicial supremacy. No debe olvidarse que la finalidad del análisis en este trabajo es conocer si la naturaleza de la Constitución implica el poder del juez para declarar su significado en forma definitiva. ${ }^{40}$

Las objeciones que quiero examinar son cuatro, y se corresponden con los argumentos analizados en el apartado anterior. Las tres primeras se dirigen a cada una de las premisas de la judicial supremacy en Marbury, que son el carácter escrito, normativo y supremo de la Constitución. La cuarta se dirige al argumento de Cooper v. Aaron, en cuanto pretende inferir lógicamente de Marbury v. Madison el carácter de intérprete supremo de la Constitución que corresponde a la Corte.

\section{A. El carácter supremo de la Constitución}

Hemos visto que la judicial supremacy significa que la Corte Suprema es el guardián último de la Constitución. La supremacía constitucional está asegurada en último término por la Corte, que tiene el poder para declarar definitivamente el sentido del texto de la Constitución. Esta condición de garante final que ostenta la Corte Suprema es, de acuerdo con la doctrina de la judicial supremacy, una exigencia intrínseca de la supremacía constitucional. Es decir, la Corte es el guardián natural de la Constitución.

El carácter normativo de la Constitución se presenta como el atributo indispensable para garantizar la supremacía de la Constitución, en el sentido de que

\footnotetext{
${ }^{39}$ Neuborne (1987), pp. 995 y ss. Para Farber, el efecto vinculante y general de las sentencias de la Corte que interpretan la Constitución se basa en la posición que tiene como tribunal federal supremo: FARBER (1982), p. 23.

${ }^{40}$ Existen otras objeciones a la judicial supremacy, de distinta naturaleza. Para tener un panorama de ellas, puede revisarse WOLFE (2004).
} 
si los tribunales no pueden defender la Constitución aplicándola como norma, entonces no es realmente suprema. Sin embargo, la supremacía es un atributo de la Constitución independiente de su carácter normativo. ¿Por qué una Constitución que no puede aplicarse como norma por los tribunales de justicia no puede (o deja de) ser suprema? La respuesta está condicionada a una definición de supremacía constitucional; pero no existe una definición única de supremacía constitucional.

Las razones que Marshall tuvo en consideración para rehusar la aplicación de una ley en nombre de la supremacía constitucional no parecen ser suficientes. Marshall invocó la voluntad de quienes elaboran una Constitución escrita como primera razón, pero aparte de que se han escrito constituciones que no son supremas en este sentido, la Constitución no es suprema sólo porque así lo quisieron quienes la promulgaron. También Marshall razonó diciendo que si la Constitución no es suprema, entonces puede ser modificada por simples leyes. Pero tampoco este argumento es satisfactorio porque, o bien la imposibilidad de alterar la Constitución por leyes ordinarias es una prueba de su supremacía (dejando la definición en la oscuridad), o bien es su definición, pero entonces Marshall falla, al no demostrar por qué la ley contraria a la Constitución es nula. ${ }^{41}$

Cabe defender la supremacía de la Constitución, aunque no se defienda su normatividad, o aunque no implique el poder de controlar la constitucionalidad de las leyes ${ }^{42}$ porque hay distintas formas de entender la supremacía. Se puede entender la supremacía de la Constitución sin asumir que su garantía descansa en último término en el Poder Judicial. ${ }^{43}$

Porque, ¿qué significa exactamente que la Constitución sea suprema? Más precisamente, ¿de qué modo la supremacía de la Constitución justifica la supre-

\footnotetext{
${ }^{41}$ Troper (2003), pp. 219 y 220.

${ }^{42}$ Cuando Marshall se ampara en la esencia del deber judicial para preferir la Constitución por sobre la ley, actúa falazmente. Porque precisamente en virtud de este deber esencial, en Francia por ejemplo, los jueces deben aplicar la ley aún cuando sea contraria a la Constitución: Troper (2003), p. 217.

${ }^{43} \mathrm{El}$ departmentalism defiende, por ejemplo, una interpretación constitucional compartida por los distintos poderes (departamentos). Por supuesto, esta aproximación a la garantía de la supremacía constitucional rechaza no sólo que el Poder Judicial sea el garante natural o necesario, sino en general todo tipo de razones que pudieran haber para justificar la judicial supremacy o la supremacía de cualquier otro poder: "The essence of departmentalism is hostility to the supremacy of any legal institution" (STITH; 2007, p. 4 nota 6). El departmentalism es una forma de comprender la garantía de la supremacía constitucional que se basa en varias razones: la primacía original del elemento político sobre el legal en la concepción de la Constitución, (Thomas; 2004); la fidelidad al diseño genuino de la Constitución (PAULSEN; 1994); la separación de los poderes (EIsGruber; 1994); su mejor adecuación a la democracia (TRibe; 2000, p. 262).
} 
macía de su intérprete judicial? Si se examina bien el texto de Marbury, no se encuentran razones que justifiquen la exclusividad del intérprete judicial, ni su carácter definitivo. ${ }^{44}$ Marbury invoca la supremacía de la Constitución para rehusar la aplicación de una ley inconstitucional; no para apoyar el efecto supremo de su interpretación de la Constitución.

Hay por lo menos dos argumentos con los que Bickel prueba que la supremacía de la Constitución no entraña necesariamente la supremacía del intérprete judicial. Marshall justificó el poder de la Corte para declarar nula una ley inconstitucional, diciendo que sería absurdo que este poder lo tuviera el Congreso. Aceptar que el Congreso se limita a sí mismo es autorizar una invitación al abuso del poder; este es el corolario que se deduce de Marbury. Pero el argumento de Marshall, dice Bickel, vale tanto más para el Poder Judicial. Porque igual que el Congreso, el judicial está limitado por la Constitución. Y si el judicial se limita a sí mismo (porque es el intérprete supremo de la Constitución), ¿̇no se está autorizando una invitación al abuso del poder? Tratándose del judicial, esto sería aún más grave que el Congreso, porque ni siquiera están sujetos al control electoral. ${ }^{45}$

El otro argumento se apoya en una crítica a la interpretación que Marshall hizo del artículo VI de la Constitución. Marshall defendió el poder de los jueces para rechazar las leyes inconstitucionales, invocando la condición de que sólo es ley aquella que es conforme con la Constitución. Pero Bickel sostiene que esta interpretación es errónea, porque la intención obvia del constituyente respecto de la supremacy clause (artículo VI) fue asegurar la supremacía de la autoridad federal sobre la autoridad estatal. Si los jueces, obligados por la Constitución, pudieran rehusar la aplicación de las leyes federales por ser inconstitucionales, el artículo VI estaría sirviendo precisamente para el fin contrario al de su creación. ${ }^{46}$

\section{B. El significado normativo de la Constitución}

Quizá el argumento más recurrido por los defensores de la judicial supremacy últimamente, sea el carácter normativo de la Constitución. ${ }^{47}$ La Constitución es ley; suprema, pero ley. Esto significa que toca al juez pronunciarse sobre su sig-

\footnotetext{
${ }^{44}$ Como bien advierte Murphy (1986), la pregunta sobre quién es el intérprete de la Constitución, depende de qué sea la Constitución y cómo deba ser interpretada. Y estas dos cuestiones admiten varias respuestas.

45 BiCKel (1986), pp. 3 y 4.

${ }^{46}$ Bickel, (1986), p. 9.

${ }^{47}$ Roosevelt III (2008), p. 1196.
} 
nificado, con carácter supremo cuando se trata de la Corte Suprema. ${ }^{48}$ La piedra angular del argumento es la afirmación contenida en Marbury para justificar la aplicación de la Constitución por parte del juez: "It is emphatically the province and duty of judicial department to say what the law is" (5 U.S. 137, 178). Se asume que la Constitución es law.

Pero este argumento merece un examen atento, porque en él parece no haber ninguna diferencia entre la ley ordinaria y la ley suprema, excepto el mayor grado jerárquico (una es ordinaria y la otra es suprema). Luego, la única diferencia entre ambas en las manos del juez sería la superioridad de la una por sobre la otra en caso de conflicto. Pero, exceptuando esta diferencia jerárquica (accidental), todo lo que implica la aplicación judicial de la ley es atribuible a la aplicación judicial de la Constitución. Sin embargo, no es así: existe una diferencia sustantiva entre la Constitución y la ley ordinaria. ${ }^{49}$ En este contexto, concuerdo con Friedman: "If living under a Constitution means anything, then it seems that separating constitutional law from ordinary law is essential" (Friedman; 2004, p. 1284)..$^{50}$

No quiero en este lugar entrar en el arduo problema de qué es la Constitución; nos contentamos con un objetivo más sencillo pero útil para esta investigación: mostrar que la Constitución es algo distinto de la ley. Quiero discutir la naturaleza normativa de la Constitución -en el sentido de que la Constitución es ley-, con el fin de derribar el carácter de causa necesaria que se le atribuye para justificar el poder de la Corte para interpretarla definitivamente.

La discusión de esta premisa de la judicial supremacy, que es el carácter normativo de la Constitución como causa de la autoridad suprema de la Corte para interpretarla, puede hacerse en dos planos. El primero es negar que la Constitución sea una ley y el segundo es negar que el carácter legal de la Constitución implique la judicial supremacy. En el contexto de este trabajo, el primer plano de esta discusión sobre el carácter normativo de la Constitución se restringirá a una perspectiva histórica. El segundo plano se ampliará a consideraciones dogmáticas.

\footnotetext{
48 "The Constitution is a legal text. Interpreting legal texts is the work of lawyers and judges, and in the ordinary case, the decision of a highest court is a definitive statement of the law": RoOSEVELT III (2008), p. 1196.

${ }^{49}$ De la esencial función del juez que es aplicar la ley, no se sigue que el juez pueda aplicar la Constitución. Una cosa es declarar lo que la ley es, y otra cosa distinta es declarar qué es ley: VAn Alstrne (1969), p. 23.

${ }^{50}$ En la página anterior se refiere a la separación entre política y Derecho que está en el origen de la crítica al judicial review. Para esta objeción al argumento de la judicial supremacy, basada en la diferencia entre Constitución y ley ordinaria, Kramer (2004).
} 


\section{La Constitución no fue originalmente concebida como ley}

La demostración de que la Constitución no es ley es un camino para enervar una de las premisas de la judicial supremacy, esa que conmuta todas las propiedades de la aplicación de la ley a la aplicación de la Constitución. Un buen punto de prueba de esta radical diferencia entre ley y Constitución es el sentido original de la Constitución como límite del legislador.

En los orígenes de la república norteamericana, la Constitución escrita fue la explicitación de la ley fundamental, esto es, la expresión del acuerdo básico que daba forma a la nueva sociedad. Por su concepción, la Constitución era manifestación del consenso político y moral. Por supuesto que su finalidad era limitar al poder soberano, pero la suya era una limitación política y moral, no jurídica.

Snowiss explica que al principio, la judicial review era esencialmente un acto político, que sustituía la reacción popular como remedio a la infracción que el legislador hacía de la ley fundamental. En el fondo, la judicial review era un sustituto pacífico de la revolución popular, un acto político. ${ }^{51} \mathrm{La}$ Constitución no fue, por lo tanto, concebida ni diseñada para ser aplicada por el juez como norma jurídica; la Constitución no era una norma jurídica.

Sin embargo, durante los años de Marshall en la Corte Suprema, la Constitución experimentó una transformación que culminó a fines del Siglo XIX en la forma moderna del judicial review. Esta transformación puede caracterizarse como un proceso de legalización, en que la Constitución pierde la connotación de Ley Fundamental y adquiere las propiedades de la ley ordinaria.

Marshall convirtió la ley fundamental que era la Constitución escrita, en la ley suprema, diferente de la ley ordinaria sólo por su mayor grado jerárquico, pero igual a ella en lo que respecta a la función judicial. Marshall logró la legalización y aplicación judicial de la Constitución tratándola como ley suprema escrita en vez de ley fundamental explícita. ${ }^{52}$

De acuerdo con su concepción original, la Constitución no puede justificar la judicial supremacy, porque carece de uno de los atributos esenciales de esta doctrina, que es el carácter legal. No hay ninguna razón necesaria para negar que

\footnotetext{
${ }^{51}$ SNOWISS (1990), p. 50.

52 SNOWISS (1990), p. 4. Esta transformación, sin embargo, no eliminó las diferencias originales entre ley fundamental y ley ordinaria, sino que las disimuló. Y por esto es que la aplicación judicial de la Constitución sigue ofreciendo dificultades que no pueden explicarse si se la comprende como ley ordinaria. Por ejemplo, la diferencia entre el judge law-making process de la aplicación de la ley y de la Constitución; la finalidad: obediencia en el caso de la Constitución, infracción en el caso de la ley.
} 
la Constitución que no es aplicable judicialmente por carecer de este atributo no es Constitución. Luego, no puede afirmarse que la judicial supremacy sea una consecuencia necesaria de la naturaleza de la Constitución, porque la Constitución no es por naturaleza -su origen así lo prueba- de carácter legal..$^{53}$

\section{El carácter legal de la Constitución no implica la judicial supremacy}

La judicial supremacy no tiene fundamento necesario en la naturaleza de la Constitución, porque la Constitución por naturaleza no es ley en el mismo sentido y con las mismas propiedades que la ley ordinaria. De hecho, esta diferencia entre la Constitución y la ley subsiste, pese a que la aplicación judicial de la Constitución como si fuera una ley es hoy una práctica habitual.

Las diferencias que subsisten entre la Constitución y la ley se pueden advertir por lo menos desde tres perspectivas: desde la perspectiva de su finalidad, de la manera de asegurar su observancia, ${ }^{54} \mathrm{y}$ de la forma de su infracción.

La finalidad que persigue la ley es distinta de la que persigue la Constitución, aunque converjan..$^{55}$ La prueba que demuestra esta diferencia es el distinto grado de tolerancia a la creación judicial del derecho (judicial policy-making), inevitable cuando se aplica la ley y la Constitución. Existe en general una mucho mayor tolerancia a la judicial policy-making que resulta de la aplicación de la ley que de la que resulta de aplicación la Constitución. La razón se debe a la distinta finalidad de una y otra norma. La satisfacción de la necesidad que subyace a la aplicación de la ley (resolver conflictos buscando la justicia del caso) es razón suficiente para tolerar los riesgos de error y judicial policy-making asociados a la aplicación judicial de la ley: es una condición para la convivencia pacífica. ${ }^{56}$ La menor tolerancia a la judicial policymaking que se sigue de la aplicación de la Constitución se debe a que no se satisface una necesidad que justifique una mayor tolerancia. La Constitución esencialmente distribuye, organiza y limita el ejercicio del poder político. La Constitución no

\footnotetext{
${ }^{53}$ En todo caso, tampoco la asimilación de la Constitución a la ley ordinaria lleva aparejada la judicial supremacy. "Understanding the Constitution as ordinary law (...) may have helped to create conditions in which an argument for judicial supremacy could more easily make headway, but it did not itself constitute any inducement to make or accept such an argument" (KRAMER; 2004, p. 155). Negar el carácter normativo de la Constitución (en cuanto asimilable a la ley ordinaria) no implica negar la posibilidad de la judicial review ni tampoco de la judicial supremacy. Aunque ambas puedan reconocer en su origen una concepción normativa de la Constitución, son cosas que se pueden separar, y que incluso puede convenir separar (SNOWISS; 2003, p. 246).

${ }^{54}$ Así hemos traducido aquí el término inglés enforcement. En otra parte de este trabajo lo hemos traducido por aplicación.

${ }^{55}$ En los países en que se postula la eficacia horizontal inmediata de la Constitución, es más difícil advertir estas diferencias en la práctica, aunque subsistan en el fondo.
}

${ }^{56}$ S Nowiss (1990), p. 198. 
está diseñada para ser aplicada por el juez como se hace con la ley, porque no está diseñada para satisfacer las mismas necesidades que la ley. ${ }^{57}$

Otra diferencia relacionada con el margen de policy-making que tiene el juez y que se puede agregar: "Judicial exposition of the law of the Constitution, operating as part of a legal check on unconstitutional legislation, generates a policy-making that, unlike that of ordinary law, conflicts with the requirements of democracy and opens judicial review to the charges of judicial supremacy and invasion of the legislative sphere" (SNOWISS; 1990, p. 9). Sin embargo, en el cumplimiento de su deber los jueces no se habían hecho merecedores de los cuestionamientos que desde hace tiempo se les dirigen, motivados por la aplicación de la Constitución. ¿̨or qué desde el momento en que los jueces aplican la Constitución la función judicial se vuelve tan problemática? Sencillamente, digo que la aplicación judicial de la Constitución amplifica en grado superlativo los problemas asociados a la aplicación judicial de la ley (v. gr. creación del derecho por medio de la interpretación de la norma). Pero además, y sobre todo, porque aplicando la ley el juez se mueve dentro de los términos fijados por el legislador (al menos, el texto), ${ }^{58}$ pero aplicando la Constitución, el juez puede enjuiciar los términos fijados por el legislador y omitir su aplicación por considerarlos contrarios a la Constitución. Si a esto se agrega que la voluntad de los jueces sustituye en este caso la voluntad del legislador, porque la sentencia que dicta tiene un efecto vinculante que alcanza a todos, entonces la explicación está completa.

El modo de garantizar la observancia de la ley difiere también del modo de garantizar la observancia de la Constitución. Porque el juez puede forzar el cumplimiento de la ley, pero no puede forzar el cumplimiento de la Constitución. En la medida que la Constitución es un límite al poder soberano, su observancia sólo es posible con la voluntaria cooperación del eventual infractor. ${ }^{59}$ Marshall se dio cuenta de que resultaba absurda la pretensión de imponer una Constitución escrita como límite al legislador. Tan absurda como pretender imponerla como límite al judicial. ${ }^{60}$

\footnotetext{
${ }^{57}$ SNOWISS (1990), pp. 199 y 200.

${ }^{58}$ En países donde la supremacía la tiene el Parlamento, la creación judicial del Derecho se ampara en la intención del legislador, aunque conste que su intención sea incompatible con la interpretación judicial de la ley. Se guardan las apariencias, como quien se cubre con una hoja de parra. Sobre el valor constitucional de esta ficción, FORSYTH (1996), pp. 136 y 137.

${ }^{59}$ El enforcement de la Constitución requiere la cooperación voluntaria de su potencial agresor (SNOWISs; 1990, pp. 104 y 105), porque sólo el poder soberano puede violar la Constitución (SNOwISS; 1990, p. 90); “... we know from history of constitutional law that courts can impose no limits on majority will the majority is not willing to accept": SNOWISS (2003), p. 244. Aquí radica la gran paradoja de la Constitución aplicada por los jueces como ley: SNOWISS (2001), p. 106.

${ }^{60}$ SNOWISS (1990), p. 121.
} 
Por último, son diferentes la ley y la Constitución en relación a su infracción. La ley es regularmente infringida y en su diseño así se prevé que sea. En cambio, la Constitución es infringida con mucha menor frecuencia, si es que puede decirse que en esos casos sea infringida. Porque, en verdad, una auténtica infracción de la Constitución es algo extremadamente raro. ${ }^{61}$

La Constitución no se entiende bien, si se entiende como ley (aunque sea suprema). Desde otro punto de vista, podríamos también decir que la supremacía de la Constitución no se entiende bien, si se entiende sólo como la posición jerárquica dentro del universo de las leyes. ${ }^{62}$ La supremacía constitucional significa algo distinto del lugar que ocupa entre los distintos rangos de normas; la Constitución significa algo distinto de la ley.

La naturaleza de la Constitución no queda satisfactoriamente explicada si se la trata de entender sólo como ley (escrita y suprema), en el sentido de que su plena actualización se verifica en su aplicación judicial. ${ }^{63}$ Con esto no rechazo la posibilidad de que la Constitución sea efectivamente aplicada por los jueces como ley, sino sencillamente afirmo que el carácter normativo de la Constitución no es causa indefectible de la judicial supremacy.

\section{La Constitución es escrita}

Aquí discuto la relación que subyace a la judicial supremacy, entre el carácter escrito de la Constitución y su interpretación definitiva por la Corte. No rechazo la idea de la aplicación judicial de la Constitución escrita, ni el carácter definitivo de la interpretación judicial de su texto. Solamente niego que la Constitución implique la judicial supremacy por ser escrita.

La primera razón para pensar esto es que la Constitución no se puso por escrito para que sea aplicada por el juez como ley. La positivización de la Constitución fue la explicitación del contrato social de la naciente sociedad; una innovación concebida principalmente para derribar la doctrina de la omnipotencia del legislador. ${ }^{64} \mathrm{El}$ significado de que la Constitución sea escrita es su explicitud, no su carácter legal. ${ }^{65}$ Pero, "In Marshall's hands the written constitution lost its (...)

\footnotetext{
${ }^{61}$ Lo que normalmente puede entenderse como una infracción de la Constitución, es en realidad reflejo de un conflicto de interpretaciones plausibles de su significado.

${ }^{62}$ La supremacía constitucional en USA es un principio anterior a la doctrina de Kelsen, por lo que sería un error tratar de entenderlo a la luz de dicha doctrina.

${ }^{63}$ SNOwISS ofrece dos pruebas de esto, en pp. 10, 11 y 198.

${ }^{64}$ SNOWISS (1990), p. 31.

${ }^{65}$ SNOWISS (1990), p. 106.
} 
meaning as vehicle of explicit fundamental law and became instead testimony to the Constitution's status as supreme ordinary law" (SNOwISs; 1990, p. 3).

El hecho de haberse puesto la Constitución por escrito no implica que sean los jueces quienes tengan la última palabra acerca de su significado. No hay una secuencia lógica entre la positivización de la Constitución y su interpretación definitiva por el juez. Ni siquiera entre la positivización y su aplicación judicial. ${ }^{66}$

Es más, podría sostenerse que al ser escrita se preserva de cualquier interpretación que pretenda hacerse de ella con carácter imperativo. La supremacía de la Constitución está mejor garantizada si la Constitución está escrita, porque así se impide que alguien pueda reclamar para sí el monopolio de su interpretación. La posibilidad de juzgar la fidelidad de la interpretación judicial de la Constitución descansa precisamente en su texto.

No debe olvidarse el caso de los países con Constitución escrita en que el intérprete supremo no es el judicial -Bélgica, ${ }^{67}$ Canadá- ${ }^{68}$ o en que el judicial no puede declarar la ley inconstitucional, como en Holanda. ${ }^{69} \mathrm{Si}$ es posible que la defensa de la Constitución escrita no esté entregada en último término al poder judicial, es porque el carácter positivo de la Constitución no exige que sea un tribunal su intérprete final.

\section{La falacia de Cooper v. Aaron ${ }^{70}$}

En Cooper, la Corte le atribuye a Marbury algo que nunca dijo expresamente y que mal puede deducirse de su texto. En Marbury, Marshall no estableció el principio de que el Poder Judicial federal era el intérprete supremo de la Constitución y que, en consecuencia, su interpretación era suprema como la Constitución. Marshall se limitó a decir que era deber de los jueces decidir entre dos leyes incompatibles, cuál de ellas debía aplicar, y aplicarla. Y si una de las leyes en conflicto era la Constitución, debía preferir la Constitución, porque es la ley suprema.

El apoyo que Marbury presta al desarrollo de Cooper no es la fuerza persuasiva de su argumentación, ni las exigencias lógicas que se siguen de la Constitución escrita,

\footnotetext{
${ }^{66}$ CAIRNS (1998) muestra que no hay una relación necesaria entre la Constitución escrita y su garantía final por un tribunal.

${ }^{67}$ Cairns (1998), p. 17.

${ }^{68}$ MASSEY (1990).

${ }^{69}$ Artículo 120 de la Constitución de 1983.

${ }^{70}$ Los diversos ataques a la sentencia -por lo menos hasta 1982- están compendiados en FARBER (1982), p. 388.
} 
sino la aceptación pública y sostenida de la innovación de Marshall: "Cooper claims only that since Marbury the judiciary has been accepted as authoritative expounder of the Constitution" (SNOWISS; 1990, p. 196).

Que la Corte se excedió en su declaración es algo que opinan incluso sus defensores. ${ }^{71} \mathrm{Si}$ la interpretación judicial de la Constitución fuera lo mismo que la Constitución, y reconociéramos que el Poder Judicial está limitado por la Constitución, ¿cómo podría justificar un cambio de su jurisprudencia? Esto prueba que no hay tal identificación: es una ficción. ${ }^{72}$

La crítica al argumento de Cooper no es en sí una crítica a la interpretación vinculante de la Constitución por parte de la Corte. Una cosa es discutir la existencia, necesidad o conveniencia de una interpretación judicial de la Constitución que sea vinculante (cosa que no hacemos aquí) y otra distinta es discutir que la causa de esta supremacía de la interpretación judicial sea la naturaleza misma de la Constitución (cosa que sí hacemos). Por esto, aunque comparto con Meese que la Constitución es distinto de lo que los jueces dicen que es, me abstengo de concluir con él que entonces como ciudadanos podemos desafiar a las sentencias con las que estemos en desacuerdo. ${ }^{73}$ Del solo hecho de que las sentencias que interpretan la Constitución no sean la misma Constitución, no nace ninguna razón para desconocerles obligatoriedad o generalidad.

En este punto hay que estar precavidos de confundir la facultad de juzgar la constitucionalidad de las leyes (judicial review) con la de interpretar definitivamente el texto de la Constitución (judicial supremacy). Son dos cosas distintas que no se implican recíprocamente. ${ }^{74}$ Incurrir en la confusión es fácil, porque hay una asociación casi espontánea entre el poder de controlar la constitucionalidad de la ley y la superioridad del que controla (judicial) respecto del que es controlado (legislador). ${ }^{75}$ Pero esto es una ilusión.

\footnotetext{
${ }^{71}$ FARBER (1982), p. 4.

${ }^{72}$ MeEse (1987a), p. 983.

${ }^{73}$ Meese (1987a), p. 985. Tradujimos to respond por desafiar. Poco después Meese matizó sus afirmaciones y reconoció que si bien las decisiones de la Corte no significan lo mismo que la Constitución, sí son "law of the land" y, como tales, tienen aplicación general y merecen el mayor respeto de todos los americanos: Meese (1987b), p. 1004.

${ }^{74}$ AleXANDer y Schauer (2005), p. 1629. Sobre las circunstancias en que la doctrina hace la conexión entre la judicial review y la judicial supremacy, WARD (2006), p. 14.

${ }^{75} \mathrm{La}$ superioridad sobre el legislador se extiende fácilmente sobre el ejecutivo, porque el ejecutivo no puede inaplicar las leyes que considere inconstitucionales. La judicial review parece suponer la judicial supremacy, porque el juez no puede invalidar un acto de un oficial electo (el congresista o parlamentario) sin que su visión de la Constitución tenga mayor valor que la que es invalidada: WARD (2006), p. 4.
} 
Es posible imaginar un tribunal declarando la inconstitucionalidad de una ley para el caso concreto sin que los motivos que tuvo para hacerlo definan los términos en que debe comprenderse en adelante la Constitución. Y esto incluso allí donde el precedente sea obligatorio para los jueces. ${ }^{76}$ También es posible suponer la vigencia de la judicial review en un esquema en que la interpretación que los jueces hacen de la Constitución esté sujeta a revisión por parte del pueblo ${ }^{77}$ o del legislativo. ${ }^{78}$

No es insensato afirmar la judicial review y negar la judicial supremacy, pero, ¿es posible sostener la judicial supremacy sin judicial review? Parece que no, porque la supremacía del Poder Judicial consiste en que su interpretación de la Constitución prevalece sobre la interpretación del Poder Legislativo. En el caso de que los jueces carecieran del poder para anular leyes inconstitucionales, no habría una supremacía de los jueces. ${ }^{79}$

En cuanto a la necesidad de una interpretación estable de la Constitución, asegurada por la aplicación uniforme que la Corte hace de ella, Bickel prueba que se satisface sin que deba aceptarse la interpretación judicial como la última palabra sobre el significado de la Constitución. ${ }^{80}$ Por su parte, Kramer discute la posibilidad de que haya una "última palabra" o certeza o estabilidad: "Uncertainty and instability will exist even in a regime of total judicial supremacy, while we find a considerable degree of finality and resolution even without it. The choice is not between order and chaos or stability and anarchy, but between different types of stability and different mechanisms for achieving it" (Kramer; 2004, p. 234). Tampoco existe una razón para optar necesariamente por el judicial para que dé la estabilidad posible, porque las instituciones políticas también desean esa estabilidad y pueden darla. ${ }^{81}$

Respecto a la posición que defiende la interpretación judicial vinculante de la Constitución con los argumentos que valen para la interpretación vinculante de la ley, hay que destacar las diferencias entre la aplicación judicial de una y otra, porque entonces los argumentos en favor de la ley no pueden transferirse sin más a la Constitución. Hay buenas razones para separar los argumentos. La primera se

\footnotetext{
${ }^{76}$ JOHNSEN (2004), p. 105.

${ }^{77}$ Kramer (2004), pp. 249-254; Tushnet (1999).

${ }^{78}$ WARD (2006), p. 4. Las razones por las que un régimen así funcionaría adecuadamente, en p. 19. También WhitTINGTON (2007), p. 7.

${ }^{79}$ Whittington (2007), pp. 5 y 6.

${ }^{80}$ BiCKel (1986), p. 12. En las pp. 10 y 11, la forma que en que puede asegurarse legítimamente la uniformidad de las leyes federales.

${ }^{81}$ Kramer (2004), p. 235.
} 
explica desde la perspectiva de su violación: la infracción de la ley es naturalmente reprimida por el juez. En cambio, una genuina infracción de la Constitución no puede ser reprimida por el juez. El segundo se explica desde la perspectiva del judicial policy-making. En el caso de la ley, el margen de creación del Derecho que tiene el juez con su aplicación es relativamente acotado. En cambio, el margen que tiene con la aplicación de la Constitución es prácticamente ilimitado. ${ }^{82} \mathrm{La}$ necesidad que justifica una exposición (o aplicación) definitiva de la ley, que es poner fin a las disputas sobre derechos, no opera respecto de la Constitución. La competencia que los jueces tienen para interpretar definitivamente la ley no la tienen respecto de la Constitución. ${ }^{83}$ Esta explicación en el fondo descubre la diferencia sustantiva que existe entre la ley y la Constitución, por lo que tratar la Constitución como si fuera una ley es un error.

\section{CONCLUSIONES}

El argumento que extrae la judicial supremacy de la naturaleza de la Constitución no es concluyente. Las premisas en que descansa la judicial supremacy tienen un significado equívoco, que habilita para concluir algo distinto. La caracterización de la Constitución no se agota en sus cualidades normativa, escrita y suprema; o el carácter normativo, escrito y supremo de la Constitución significa algo más que lo postulado por la doctrina de la judicial supremacy.

La Constitución es una realidad que no admite ser comprendida según las características de la ley. La Constitución tiene una dimensión legal, pero no se reduce a ella. De la aplicación judicial de la Constitución ni se deduce ni se sigue que esta sea ley, aunque en este ámbito pueda participar de sus propiedades. Qué sea la Constitución es una cuestión que no se responde aquí sino en forma negativa: la Constitución no es ley. Positivamente, sólo me atrevo a decir que la función normativa de la Constitución es de naturaleza distinta a la función normativa de la ley.

Tampoco la Constitución es suprema, en el sentido de ser la norma de mayor jerarquía dentro del rango de las leyes. La supremacía de la Constitución puede suponer la obligación del juez de preferirla frente a una ley con ella incompatible, pero también puede no suponerla. La supremacía no significa ni necesaria ni exclusivamente la superioridad de la Constitución sobre la ley, aunque éste pueda ser uno de sus efectos. El carácter supremo de la Constitución tiene una connotación política, que amplía su función más allá que la de adjetivar una ley.

\footnotetext{
${ }^{82}$ SNOWISS (1990), pp. 198-200.

${ }^{83}$ SNOwISS (2003), pp. 236 y 237.
} 
La defensa jurisdiccional de la Constitución, incluso en un esquema en donde la interpretación judicial es la definitiva, garantiza la Constitución en la medida en que los jueces pueden hacerlo. Más allá de los argumentos que sustenten la judicial supremacy, esta forma de asegurar la Constitución siempre estará sujeta a los límites naturales de la función judicial. La Constitución que es interpretada y aplicada por los jueces es la Constitución que puede ser interpretada y aplicada por los jueces, pero eso no es la Constitución, sino una dimensión de ella. Esto significa que la Constitución no se identifica con lo que los jueces dicen que es; significa que la Constitución es también límite del judicial y que, por lo tanto, la supremacía del judicial es relativa.

\section{BiBLIOGRAFÍA CITADA}

AleXANDER, Larry y Schauer, Frederick (1997): “On Extrajudicial Constitutional Interpretation", en Harvard Law Review, (Vol. 110), pp. 1377-1388;

Bickel, Alexander (1986): The Least Dangerous Branch. The Supreme Court at the Bar of Politics, ( $2^{\text {nd }}$ ed., Yale University Press, New Haven), 303 pp;

BlaCK, Charles (1960): The People and the Court. Judicial review in a Democracy, (Prentice-Hall, New Jersey), 238 pp;

CaIrns, Walter (1998): "Does a Written Constitution Require a Constitutional Court?”, en Bracton Law Journal (Vol. 30), pp. 13-22;

Clark, A. Inglis (1903): "The supremacy of the judiciary under the Constitution of the United States, and under the Constitution of the common-wealth of Australia”, en Harvard Law Review, (Vol. XVII No 1), pp. 1-19;

Cuinton, Robert (1989): Marbury v. Madison and Judicial Review, (University Press of Kansas, Kansas), 332 pp;

DAJOvIC, Goran (2010): "The Rule of Recognition and the Written Constitution", en Annals of the Faculty of Law in Belgrade, Belgrade Law Review (Vol. 2010), pp. 248-264;

DiCEY, Albert Venn (1902): Introduction to the Study of the Law of the Constitution, (6 $6^{\text {th }}$ ed., London, Macmillan and Co.), 533 pp;

Eisgruber, Christopher (1994): "The Most Competent Branches: A Response to Professor Paulsen”, en Georgetown Law Journal, (Vol. 83 Issue 2), pp. 347-372;

Farber, Daniel (1982): "The Supreme Court and the Rule of Law: Cooper v. Aaron revisited", en University of Illinois Law Review, (Vol. 1982 No 2), pp. 387-412.

Forsyth, Christopher (1996): "Of Fig Leaves and Fairy Tales: The Ultra Vires Doctrine, the Sovereignty of Parliament and Judicial Review" en Cambridge Law Journal, (Vol. 55, Issue 1), pp. 122-140; 
Freyer, Tony (2008):“The Little Rock Confrontation and Cooper v. Aaron: Development and Implementation of Constitutional Litigation", en University of Arkansas at Little Rock Law Review, (Vol. 30, Issue 2), pp. 323-344;

Friedman, Barry (2004): "The Importance of Being Positive: The Nature and Function of Judicial Review", en University of Cincinnati Law Review, (Vol. 72, Issue 4), pp. 1257-1304;

HaInes, Charles G. (1959): The American doctrine of judicial supremacy $\left(2^{\text {nd }}\right.$ ed., Russell \& Russell, New York), 705 pp;

Hughes, Charles (1908): Addresses and Papers of Charles Evans Hughes, governor of New York, 1906-1908, Jacob Gold Schurman (ed.), (Putnam's Sons, New York), $289 \mathrm{pp}$;

JaKsON, Robert (1949): The Struggle for Judicial Supremacy, (Alfred Knopf, New York); $361 \mathrm{pp}$;

JoHnsen, Dawn (2004): "Functional Departmentalism and Nonjudicial Interpretation: Who determines constitutional meaning?", en Law and Contemporary Problems, (Vol. 67, Issue 3), pp. 105-148;

Kent, James (1896): Commentaries on American Law, (14 $4^{\text {th }}$ edition, 4 Vols., Little Brown \& Co., Boston);

KilpATRICK, JUdiTH (2008): “Cooper v. Aaron: Development and Implementation of the Litigation" en University of Arkansas at Little Rock Law Review, (Vol. 30, Issue 2), pp. 355-362;

Kramer, Larry (2004): The People Themselves. Popular Constitutionalism and Judicial Review, (Oxford University Press, New York), 363 pp;

Massey, Calvin R. (1990): "The Locus of Sovereignty: Judicial Review, Legislative Supremacy, and Federalism in the Constitutional Traditions of Canada and the United States", en Duke Law Journal (Vol. 1990, Issue 6), pp. 1229-1310;

McDowell, Gary (2010): The Language of Law and the Foundations of American Constitutionalism, (Cambridge University Press, New York), 409 pp;

Meese, Edwin (1987a): "The law of the Constitution", en Tulane law Review, (Vol. 61), pp. 979-990;

MeesE, Edwin (1987b): "The Tulane Speech: What I Meant", en Tulane law Review, (Vol. 61), pp. 1003-1007;

Neuborne, Burt (1987): "Binding Quality of Supreme Court Precedent", en Tulane Law Review (Vol. 61), pp. 991-1002;

O'SCannlain, Diarmuid (2005): "Is a Written Constitution Necessary?", en Pepperdine Law Review (Vol. 32, Issue 4), pp. 793-800;

Paulsen, Michael (1994): "The Most Dangerous Branch: Executive Power to Say What the Law Is", en Georgetown Law Journal (Vol. 83 Issue 2), pp. 217-346; 
Roosevelt III, Kermit (2008): "Judicial supremacy, judicial activism: Cooper v. Aaron and Parents Involved", en Saint Louis University Law Journal, (Vol. 52), pp. 1191-1210.

SNOwISS, Sylvia (1990): Judicial review and the law of the Constitution, (Yale University Press, New Haven), 228 pp.

SNOWISS, Sylvia (2001): "The Constitution as law: problems and paradox", en AA.VV., Le droit dans la culture americaine, (LGDJ, Paris), pp. 79-108;

SNOWISS, Sylvia (2003): "The Marbury of the 1803 and the modern Marbury", en Constitutional Commentary, (Vol. 20), pp. 231-254;

STITH, Richard (2007): "Securing the Rule of Law through interpretative pluralism: an argument from comparative law", en Jean Monnet Working Paper 01/07, pp. 1-37, disponible en http://centers.law.nyu.edu/jeanmonnet/ papers/07/070101.pdf;

STORY, Joseph (1833): Commentaries of the Constitution of the United States, (3 vols., Hilliard, Gray and Company, Boston);

Thomas, George (2004): "Recovering the Political Constitution: The Madisonian Vision", en The Review of Politics (Vol. 66 Issue 2), pp. 233-256;

TRIBE, Laurence (2000): American Constitutional Law ( $3^{\text {rd }}$ ed., Foundation Press, New York), 1470 pp;

Troper, Michel (2003): "Marshall, Kelsen, Barak et le sophisme constitutionnaliste”, en Marbury v. Madison: 1803 - 2003 Un dialogue Franco-Américaine, (Dalloz, Paris), pp 215-228;

Tushnet, Mark (1999): Taking the Constitution away from the Courts (Princeton University Press, New Jersey), 242 pp;

Van Alstyne, William (1969): “Critical Guide to Marbury v. Madison”, en Duke Law Journal (Vol. 1969, Issue 1), pp. 1-48;

WARD, Kenneth (2006): "Legislative Primacy: A Neglected Alternative to Judicial Supremacy", disponible en http://ssrn.com/abstract=899607

Whittington, Keith (2007): Political foundations of judicial supremacy, (Princeton University Press, New Jersey), 303 pp;

Wolfe, Christopher (ed.) (2004): That eminent tribunal: judicial supremacy and the Constitution, AA.VV., (Princeton University Press, New Jersey), 238 pp;

\section{Jurisprudencia citada}

Kamper v. Hawkins 1 Va. Cases 20 (1793) disponible en http://www.virginia1774. org/Kamperv.Hawkins3.html

Marbury v. Madison 5 U.S. (1Cranch) 137 (1803) disponible en http://supreme. justia.com 
Graves v. New York 306 U.S. 466 (1939) disponible en http://supreme.justia. com

Cooper v. Aaron 358 U.S. 1 (1958) disponible en http://supreme.justia.com

Hutchinson v. United States 369 U.S. 599 (1962) disponible en http://supreme. justia.com

Baker v. Carr 369 U.S. 186 (1962) disponible en http://supreme.justia.com

Bell v. Maryland 378 U.S. 226 (1964) disponible en http://supreme.justia.com

United States v. Nixon 418 U.S. 683 (1974) disponible en http://supreme.justia. com

City of Boerne v. Flores 521 U.S. 507 (1997) disponible en http://supreme.justia. com

Dickerson v. United States 530 U.S. 428 (2000) disponible en http://supreme. justia.com 